\title{
Assisted dying
}

\author{
Raymond Hoffenberg
}

Sir Raymond Hoffenberg KBE FRCP FFPM, Past President, Royal College of Physicians

Clin Med 2006:6:72-74

\begin{abstract}
The Royal College of Physicians took a neutral position on the House of Lords Assisted Dying for the Terminally III Bill. While modern palliative care and the hospice approach have greatly reduced terminal suffering, they do not always achieve total relief of distressing symptoms - the majority of dying patients and their families probably do not receive optimal terminal care. In this article I try to rebut the common arguments against assisted dying and add some arguments in favour. I suggest that on this issue the medical professions are out of tune with majority public opinion.
\end{abstract}

KEY WORDS: assisted dying, euthanasia, terminal illness

\section{Assisted dying}

On 4 April 2005, the House of Lords published its Select Committee's report on the Assisted Dying for the Terminally Ill Bill. The Bill was of interest to me for two reasons. First, it was introduced by an old friend of mine, Lord Joffe. Second, and far more compelling, was my long-standing conviction that a Bill of this sort was necessary.

The Select Committee sought the views of the public and received over 14,000 responses, reflecting widespread and intense interest in the topic. Among these was the response of the Royal College of Physicians of London (RCP), submitted on behalf of the Academy of Medical Royal Colleges, and a personal submission from me. Before I re-present the arguments I put forward, I shall comment on the College's response.

\section{The College's view}

The RCP drew attention to the diversity of views about assisted dying and reported overwhelming agreement that the Bill was essentially a matter for 'society as a whole'. For these two reasons they decided not to commit themselves for or against its proposals. Diversity of opinion is, of course, to be expected in all ethical dilemmas; if there were no diversity and everyone were to agree that there was an absolute right or wrong course of action in a particular case it would no longer be an ethical dilemma.
The existence of diverse views should not in itself inhibit the College from expressing an opinion about what it thinks would be the best course; this has not previously prevented it from doing so in numerous statements and publications on ethical issues. In this instance it might have been helpful to have provided some general indication of the Committee's views by stating the number of its members who were in favour of, or opposed to, the Bill.

I agree with the College's view that most, if not all, ethical problems are of concern to society as a whole, but it makes sense to pay somewhat more attention to the opinions of those who have special experience or knowledge. As practising doctors, most of us have seen more of death and dying than we might have wished; not only have we looked after dying patients but we have listened to and tried to support their families before and after their loss. This surely adds weight to the views we express, in my opinion considerably more than comments based on belief or emotion without any direct experience. In confining its response to purely medical issues, in which the profession may justly claim to have special understanding and expertise, the College seems to be showing undue modesty.

\section{A personal view}

In my personal submission I eschewed such modesty and tried instead to address the objections people commonly make to the practice of assisted dying to see to what extent I could rebut them or, at least, mitigate the arguments behind them.

The objective of the Bill is to provide a lawful way of alleviating the plight of terminally ill patients who are suffering intolerably, despite appropriate medical treatment. The strongest objections come from palliative care specialists and other doctors involved in care of the dying. Their view is that such suffering can be overcome by proper, efficient palliative care: modern therapy can always relieve physical pain, and the hospice approach is able to provide the emotional, social and spiritual comfort that characterises a 'good' death.

There can be no doubt that the hospice movement has made a tremendous contribution and modern palliative care is able to alleviate much of the suffering that accompanies the process of dying. The reality is, however, that the majority of dying patients 
do not have access to optimal terminal care. Richard Smith, late editor of the British Medical Journal, wrote:

For the minority who die under the care of palliative teams it is probably good, but there is a suspicion that for the majority who die in acute hospitals or nursing homes the experience is bad. ${ }^{1}$

For many who die at home it is almost certainly worse. As a member of an age group from which one increasingly loses one's friends and relatives, I hear far too many stories of unsatisfactory terminal care to feel complacent about the way we manage dying. Anecdotes, it is true, and admittedly I only hear one side of the story, but there is enough substance from reliable witnesses to suggest a mismatch between the care doctors believe they are giving, and what patients themselves think - surveys tend to confirm this. Whereas palliative care specialists claim to control pain and suffering in almost all cases, between 5 and $35 \%$ of terminally ill patients have reported 'severe' or 'unbearable' pain in spite of treatment. Breathlessness, nausea and vomiting are hard to control, and loss of capability and independence and/or loss of sphincter control are extremely distressing and not easily palliated.

\section{Doctors and patients}

Of general concern, and specifically mentioned in the College report, is the impact the Bill might have on the relationship between doctors and their individual patients or between the profession and society in general. The implication is that doctors belong to a caring profession whose function is to treat and heal the sick and suffering. If they are known to assist in shortening the life of their patients ('killing' them in the terminology of opponents of assisted dying) this relationship will be undermined. The opposite, however, may well be true: the public might welcome, and be comforted by, the thought that their doctors would be prepared to assist them to die if they requested it because of intolerable suffering. Providing relief in these circumstances is not an abrogation of one's duty to care; on the contrary, it could be seen as an extension of this responsibility.

In those countries which have legalised assisted dying or euthanasia, there is no evidence to support a decline in the patient-doctor relationship. In the Netherlands, the percentage of people in favour of continuing the practice has increased steadily over the years. In Britain, the number in favour of euthanasia rose from about $50 \%$ in the 1960 s to about $80 \%$ after the Cox and Bland cases in the 1990s; a recent report found that $87 \%$ of people in Britain want the law changed to allow medical intervention to help people to die. Surveys of elderly people in Australia a few years ago, in which I took part, demonstrated similar strong support.

Another commonly voiced argument is that voluntary euthanasia might become involuntary, that vulnerable members of society - the elderly, disabled, mentally incompetent or other 'unwanted' people who have simply become a burden - might be placed at risk of disposal against their wishes. Various forms of pressure might be applied by uncaring relatives or others to induce them to request early death. Pressure might also be applied to doctors - the option of assisting the dying process mutating into a duty to do so.

In a civilised society it is highly unlikely that a doctor other than a criminal (Harold Shipman, for example) would acquiesce in the involuntary killing of individuals. The intention of the Bill is to confine assistance in dying to those who meet the required medical criteria and have requested it in writing or have incontrovertibly expressed their desire for it while mentally competent; it would not be permitted without such evidence. It is impossible to completely eliminate the effects of pressure, direct or implied, but the safeguards outlined in the Bill, if followed meticulously, should do so.

The idea that voluntary requests for assisted death would inevitably merge into involuntary exploitation of the vulnerable is based on the slippery slope argument that practice A will inevitably lead to practice $B$. There is no evidence of this 'inevitable' trend in countries that allow euthanasia. In any event, the argument is inherently flawed: if practice A (acceding to a voluntary request) is accepted or desired but practice $\mathrm{B}$ (involuntary disposal of people) is not, it makes little sense to ban A simply to prevent B. The correct action is to retain A but to outlaw B - to apply stringent scrutiny and proper recording of all requests and impose appropriate punishment of those who transgress.

Reference is occasionally made to the risk of medical error in diagnosis or prognosis - cases are cited in which patients regarded as terminal have recovered and returned to normal life. Similarly, there are doubts about the validity of determining mental competence in terminally ill patients, on which the authenticity of a request is dependent. These points are covered in the College response, and the detailed provisions of the Bill should help to keep error to a minimum. For instance, the opinion of another physician and specialist in palliative care is required to confirm the diagnosis and prognosis before a decision is taken, and close observation is necessary over a period of 14 days from the time the request is made. The question of mental competence is covered by the need to have it confirmed by two doctors, a solicitor and a witness; if there is any doubt, a psychiatric referral is mandatory.

The final objection is made on religious grounds: life is sacred and dying is a process in which doctors - or anyone else - should not intervene. It stands to reason that there should be a conscience clause; no doctor should be obliged to carry out any measure that is contrary to a firmly held belief or principle. Whether a general prohibition should be applied to those who do not share this view is questionable.

\section{Autonomy}

In present day ethics, paramount importance is accorded to the principle of autonomy. Competent patients may decide whether or not to accept treatment and may reject it even if it is thought to be life-saving. They have the power to make decisions about all aspects of their care but they are not able to demand treatment regarded by their doctors as harmful or valueless. They have the right to refuse food and water, and so to die from 
inanition or dehydration. Thus, they may elect to die a slow and distressing death but having made the decision to end their lives, they are denied the means to achieve this expeditiously. In this critical decision, knowing that they are dying, they are denied autonomy - the right to choose how and when they do so.

It is usually agreed that there is very little ethical (as opposed to legal) distinction between allowing patients to die by withholding or withdrawing treatment and taking more active steps to end their lives. In both cases the intent is the same, only the means of achieving it is different. Following the Bland case, the House of Lords gave consent in certain circumstances for the withdrawal of food and water from patients in a persistent vegetative state - death follows about ten days later. During this time relatives have to watch the slow inexorable extinction of life, nursing staff have to wash, turn, toilet and generally tend what they know to be an incipient corpse. In such cases, would it not be more humane to expedite the process of dying? Could this question not be asked about dying in general? We would not hesitate to expedite death if we were dealing with a domestic animal. Why do we insist that humans must suffer?

Those of us who remember the days before legalisation of abortion will recall how frequently the procedure was carried out covertly by doctors - and others. There is a parallel with assisted dying. Despite a recent statement from the British Medical Association that it had no evidence of covert euthanasia, many doctors - good caring doctors - do practice it. They usually do so in the guise of the double-effect principle, using large doses of a drug to relieve symptoms knowing that this might shorten life. In many cases the true intention is to achieve the latter; were they to disclose this, they would face serious legal and professional condemnation. A decision to allow assisted dying as outlined in the Bill would obviate a moral and legal contrivance behind which many doctors shelter.

\section{Closing remarks}

As a final comment, I would submit that doctors and other health professionals are not always in tune with the thinking of their patients. A few years ago I took part in a large survey carried out in Queensland of the views of doctors and their patients about end-of-life decisions:

- $57 \%$ of general practitioners believed their patients would prefer to leave such decisions to the doctor; only $14 \%$ of the public held this view

- $62 \%$ of patients were in favour of assisted dying compared to $30 \%$ of doctors

- $65 \%$ of patients felt the law should be changed to allow the process; a recent figure from Britain is $87 \%$.

There is little doubt that a substantial majority of the public is in favour of measures to permit assisted dying. If they had the support of the medical profession, it is likely this Bill would be passed; our professional resistance is one of its strongest obstacles. Is our opposition really justified?

\section{Reference}

1 Smith R. A good death. BMJ 2000;320:129-30. 